\title{
INTRODUÇÃO. EPISTEMOLOGIAS E METODOLOGIAS FEMINISTAS EM PORTUGAL: CONTRIBUTOS PARA VELHOS E NOVOS DEBATES
}

\author{
Maria do Mar Pereira e Ana Cristina Santos ${ }^{2}$
}

Universidade de Warwick, Reino Unido Universidade de Coimbra, Portugal

Desde a sua emergência, uma das principais missões da investigação feminista tem sido desenvolver um projeto interdisciplinar de análise crítica dos pressupostos epistemológicos e dos princípios e procedimentos metodológicos da ciência dita mainstream. É notório e inegável que, em muitos países e áreas de estudo, esta crítica feminista gerou ao longo das últimas décadas inovações importantes: dela têm resultado não só novos conceitos e métodos de investigação, mas também propostas substanciais e inovadoras de reestruturação dos paradigmas dominantes de concetualização do conhecimento científico. Como argumenta Terry Threadgold, «[n]ão há uma única disciplina nas Humanidades ou nas Ciências Sociais que não tenha sido afetada de alguma forma pela reflexão e investigação feminista dos últimos 30 anos» (2000: 46).

No entanto, este projeto feminista de crítica metodológica e epistemológica não é linear nem consensual e, apesar dos seus inegáveis avanços, permanece inacabado. Com a publicação deste dossiê temático, a ex aequo propõe-se criar um espaço internacional e interdisciplinar para debater o pensamento feminista sobre epistemologia e metodologia ${ }^{3}$. O dossiê procura assim contribuir para o aprofundamento de um conjunto de discussões que nos parecem fundamentais por três razões, sobre as quais nos debruçamos seguidamente.

\section{O Estatuto e (Falta de) Reconhecimento da Crítica Epistemológica e Meto- dológica Feminista em Portugal}

Em Portugal, autoras/es feministas têm feito um grande esforço de desconstrução da produção científica nacional em diferentes disciplinas, e de criação de epistemologias e metodologias feministas (disciplinares ou interdisciplinares) inspiradas em propostas internacionais ${ }^{4}$ adaptadas ao contexto português. Veja-se,

1 University of Warwick, Department of Sociology, Coventry, CV4 7AL, Reino Unido. m.d.m.pereira@warwick.ac.uk

2 Centro de Estudos Sociais, Universidade de Coimbra. cristina@ces.uc.pt

3 As duas autoras, coordenadoras deste dossiê temático, gostariam de agradecer ao Conselho de Redação da ex aequo (pelo entusiasmo com que acolheram a proposta de dossiê e pelo apoio prestado ao longo da sua preparação), a todas/os as/os autoras/es que submeteram artigos e às/aos colegas de vários países que avaliaram essas submissões.

1 Um importante contributo para este trabalho de reinterpretação e reapropriação de propostas 
por exemplo, o trabalho de Lígia Amâncio (1994, 2001, 2003), Helena Costa Araújo (2002), Adriana Bebiano (Bebiano et al., 2009; Bebiano e Ramalho, 2010), Madalena Duarte (2013), Virgínia Ferreira (2004), Laura Fonseca (2001), Teresa Joaquim (2001, 2007), Ana Gabriela Macedo e Ana Luísa Amaral (Macedo, 2012; Macedo e Amaral, 2002, 2005), Maria José Magalhães (1998, 2005), Sofia Neves (2010, 2012; Neves e Nogueira, 2004, 2005), Conceição Nogueira (2001a, 2001b, 2012), João Manuel de Oliveira (2009, 2010, 2012; Oliveira, J.M.d. e Amâncio, 2006), Maria do Mar Pereira (2012a), Teresa Pinto (2008), Maria Irene Ramalho (2001), Ana Cristina Santos (2006, 2012), Maria Johanna Schouten (2011), Manuela Tavares (2011; Tavares et al., 2012) e Miguel Vale de Almeida (1995; Vale de Almeida et al., 1996).

Este conjunto de intervenções afirma-se já como um sólido, diversificado e amadurecido corpus de reflexão feminista, e tem servido de base para a consolidação da investigação e ensino em estudos sobre as mulheres, de género e feministas (EMGF) em Portugal. No entanto, o seu reconhecimento e impacto para além da área, embora crescente, é ainda relativamente limitado. Analisando a forma como o género é estudado à escala nacional, várias/os autoras/es têm demonstrado que na produção científica dominante continua a entender-se a análise de género como a comparação entre sexos para descrever aquilo que os diferencia, o que produz uma problemática ampliação, reificação e dicotomização dessas diferenças (Amâncio, 2003; Joaquim, 2004; Neves, 2012; Nogueira, 2001b; Oliveira, J.M.d., 2012; Pereira, 2012a; Vale de Almeida et al., 1996). Esta tendência parece indicar que a crítica feminista não resultou ainda numa efetiva mudança de paradigma no discurso sobre género nas ciências sociais e humanidades em Portugal. Como argumenta Joaquim,

A categoria analítica de género tornou-se mais presente em Portugal nos anos 90 (...). Tornou-se numa palavra passe-partout, nomeadamente na sua emigração e tradução em contextos institucionais cuja utilização - nessa tradução institucionalizada - é muitas vezes indevida, por escamotear a crítica que essa categoria analítica implícita, podendo-se fazê-la 'despolitizar' a luta das mulheres. [É uma clategoria analítica que se tornou um contributo teórico importante, mas que não é reconhecido na sua fonte, que é 'cortada' da área dos estudos sobre as mulheres, das teorias feministas, havendo neste caso a despolitização também do conceito. (2004: 89)

Investigação etnográfica recente produzida por uma de nós (Pereira, 2012b) contribui para explicar como e por que é que este «corte» acontece. Com base em observação participante em mais de 50 eventos científicos e entrevistas com quase 40 académicas/os e estudantes (conduzidas entre 2008 e 2009), foram analisados os discursos que circulam no meio académico português sobre o estatuto epistémico dos EMGF (isto é, sobre a validade, credibilidade e pertinência dos EMGF

estrangeiras tem sido dado por um conjunto de traduções para português de textos canónicos (como, por exemplo, Araújo et al., 2003; Levy e Queiroz, 2006; Macedo, 2002). 
enquanto conhecimento científico). Examinando como é que as/os académicas/os fora dos EMGF falam sobre a área em contexto de sala de aula, conferências e reuniões, demonstra-se que a grande maioria afirma que a área produz conhecimento válido e pertinente, mas só até certo ponto ou em algumas condições.

Este discurso de reconhecimento condicional retrata os EMGF como uma área que está parcialmente dentro e parcialmente fora das fronteiras do conhecimento científico «a sério». Por outras palavras, a área é vista como incluindo contributos que são epistemicamente valiosos e outros que vão «longe demais», isto é, que estão para lá da fronteira que alegadamente separa o conhecimento que é científico (e que, portanto, deve ser reconhecido, desenvolvido, citado, ensinado) daquele que não o é. Geralmente, os elementos dos EMGF que estas/es investigadoras/es consideram que vão «longe demais» são precisamente as críticas epistemológicas e metodológicas ao conhecimento dominante produzidas pelas/os autoras/es feministas (Pereira, 2012b).

Esta caracterização dos EMGF gera e possibilita um «corte epistémico» (epistemic splitting) dos EMGF, isto é, produz uma separação entre elementos dos EMGF que as/os investigadoras/es feministas consideram inseparáveis (Pereira, 2012b). Permite, por exemplo, separar o conceito de género das críticas feministas de caráter epistemológico, teórico e político que estão na origem do desenvolvimento do conceito, com base no argumento de que essas críticas são epistemicamente deficientes e, como tal, podem ser legitimamente ignoradas ou descartadas. Esta manobra permite à investigação científica dominante utilizar conceitos e contributos feministas, mas contornar a crítica feminista aos seus princípios epistemológicos e metodológicos. Torna-se, assim, possível utilizar o conceito de género e fazer análise de género sem uma efetiva mudança de paradigma epistemológico e metodológico - como denunciam Joaquim (2004) e as/os outras/os autoras/es referidas/os acima. Consideramos, portanto, que é urgente continuar a fortalecer o debate sobre epistemologia e metodologia feminista, de forma a desenvolver estratégias para resistir a esta apropriação seletiva do pensamento feminista.

\section{O Debate sobre Epistemologia e Metodologia Feminista em Portugal}

Como salientam Fonow e Cook (2005) e Harding e Norberg (2005), entre outras/os autoras/es, não existe uma metodologia e epistemologia feminista consensual e homogénea, e o debate entre feministas sobre os méritos e limitações de diferentes abordagens tem sido intenso e frutífero. No entanto, apesar da existência de um corpus consolidado de reflexão feminista sobre epistemologia e metodologia, é frequente ouvir dizer que não existe debate epistemológico e metodológico em Portugal, tanto dentro como fora dos EMGF. Nos finais dos anos 1990, António Sousa Ribeiro e Maria Irene Ramalho escreviam, 
Não tem sido muito viva entre nós a reflexão sobre a situação epistemológica das Ciências Sociais e das Humanidades (...). São, de facto, por norma bastante escassas no nosso contexto as tentativas relevantes de trazer à discussão (...) O sentido, potencialidades e limites dos contextos paradigmáticos em cada momento vigentes. Daqui resulta um dos aspectos sem dúvida mais perturbadores da vida intelectual portuguesa: a forma como as transições de paradigma ou, simplesmente, a adopção deste ou daquele modelo teórico ou metodológico se vão fazendo de acordo com uma lógica indiscutida (...). (1998/1999: 80)

Um/a investigador/a sénior entrevistada/o no âmbito do estudo etnográfico anteriormente citado (Pereira, 2012b) descreve este facto como um resultado da dimensão relativamente pequena da comunidade académica em Portugal:

O debate científico [em Portugal] é cerceadíssimo, não é, as pessoas dependem muito umas das outras, dependem muito, muito umas das outras. Têm aquelas, como é que se chamam, os não sei quantos graus de separação são rapidíssimos, as pessoas conhecem-se, têm relações familiares, dependem muito dos favores umas das outras, não querem chatear para depois não serem chateadas, enfim, tudo o que a gente sabe sobre uma sociedade pequena. E portanto as coisas não se dizem e não se debatem muito, mas depois ouvem-se as conversas das pessoas e percebe-se que [as críticas] acontecem.

Este é considerado também um traço característico dos EMGF em Portugal. De facto, uma das afirmações feitas mais frequentemente em conferências, em textos escritos, e nas entrevistas realizadas por Pereira (2011), é a de que na investigação portuguesa em EMGF há uma falta de debate epistemológico e teórico aprofundado (Ferreira, 2001; Joaquim, 2001; Magalhães, 2001; Pinto, 2007b; Tavares et al., 2012). Marianne Grünell e Erna Kas descrevem Portugal como um país com «investigação feminista cordial», citando um comentário feito por Teresa Joaquim em situação de entrevista: «[a]qui o clima intelectual é caracterizado por co-existência ou indiferença. Também se pode dizer que somos muito cordiais e bem-educadas. É esse o caso também nos estudos sobre as mulheres: não há tradição de discussão teórica» (Joaquim, citada em Grünell e Kas, 1995: 543). Lígia Amâncio também discute esta questão, escrevendo que «nunca é demais acentuar» que a «riqueza» do debate que caracteriza os EMGF nos Estados Unidos da América não tem paralelo em Portugal (2001: 21). Também ela atribui esta diferença à dimensão relativamente pequena da comunidade académica em Portugal, e à sua «estranha associação entre debate e conflito - interpessoal ou institucional» (Amâncio, 2002: 57), que faz com que o debate epistemológico e teórico seja condicionado por, e gerador de, tensões pessoais e institucionais. Todas as pessoas entrevistadas por Pereira (2011) que se referiram a esta falta de debate descreveram-na como um constrangimento nocivo ao desenvolvimento da investigação em EMGF. Algumas/uns entrevistadas/os 
salientaram que nos últimos anos se têm feito esforços - nomeadamente através da ex aequo (Nogueira, 2004; Pinto, 2007a, 2009) e do Congresso Feminista, organizado pela União de Mulheres Alternativa e Resposta (UMAR) em 2008 - para promover o debate escrito ou público nos EMGF, mas explicaram que estes esforços (ainda) não tinham dado tantos frutos como seria desejável.

No entanto, esta é apenas uma parte de uma história bem mais complexa. Várias/os entrevistadas/os explicaram que a «cordialidade» pública e falta de debate aberto coexiste com um cenário diferente nos contextos menos públicos. Segundo elas/es, nesses contextos verifica-se uma frequente produção de discussões epistemológicas e metodológicas, muitas vezes com avaliações mordazes do valor relativo de diferentes abordagens. Um/a investigador/a sénior em EMGF ofereceu o seguinte relato dessas discussões:

Sempre houve em Portugal, nas ciências sociais em geral, e nesta área [dos EMGF] também, uma dificuldade de assumir o debate, não se assumem as diferenças, as divergências metodológicas e até epistemológicas, quero dizer, assumem-se, mas só internamente. (...) Não se confrontam umas com as outras, cara a cara. (...) Isso é muito prejudicial, porque as pessoas fazem avaliações à socapa das investigações dos outros, mas não as confrontam, e as pessoas não têm possibilidade de se defender e argumentar. E mais ainda, aquela investigação como é desvalorizada, também não é potencializada para a área, percebes? E portanto isso é quase como se ela não existisse, e portanto não se potencia o debate e o desenvolvimento da área.

Este é, de facto, a nosso ver, um dos grandes desafios que se colocam à investigação feminista em Portugal na atualidade. O debate e crítica são elementos vitais e generativos da produção de conhecimento feminista. Como argumenta a antropóloga Marilyn Strathern, «o feminismo reside no próprio debate» (1988: 24). Como tal, consignar o debate metodológico e epistemológico às «conversas de corredor $»^{5}$ limita profunda e problematicamente o espaço de crescimento da investigação feminista, e impossibilita as trocas e confrontos de ideias que catalizam a inovação.

\section{Interdisciplinar para Indisciplinar: o Potencial Disruptivo da Epistemolo- gia e Metodologia Feministas (também) em Portugal}

A terceira e última razão que justifica a urgência da reflexão proposta neste dossiê reside justamente no caráter simultaneamente académico e político dos EMGF. Por motivos de síntese, propomo-nos desdobrar esta razão em dois elementos: posicionalidades porosas; e temas emergentes.

5 Utilizamos o termo aqui no sentido que lhe é dado por Gary Downey et al.: «o não dito, mas frequentemente dito na mesma (mas não a toda a gente)» (1997: 245). 
Tal como em outros temas não dominantes cujas propostas hermenêuticas exigem validação empírica rigorosa ancorada em fontes primárias de informação ${ }^{6}$, os EMGF estão tão próximos do seu objeto/sujeito de estudo que as fronteiras entre ambos se tornam particularmente porosas. Assim, movimentos sociais, academia, jornalistas e agentes de decisão política, entre outros exemplos, estão frequentemente em estreita articulação na produção de conhecimento e na prática feminista. Acresce que essa porosidade, mais do que envergonhada, é acolhida com a segurança que decorre da premissa de que todo o conhecimento é situado (Haraway, 1988) e que do reconhecimento dessa posicionalidade resulta uma das mais fortes propostas dos EMGF. Tal reconhecimento do caráter situado e, logo, político, de toda a intervenção teórica, incluindo a feminista, conduz a uma aproximação entre academia e tudo o que está para além dela, confrontando a tradicional disciplina académica - plasmada em unidades curriculares, áreas de conhecimento, linhas de financiamento, etc. - com a inevitabilidade da indisciplina com que se tecem os dias.

E aqui começa a delinear-se o segundo elemento que caracteriza o potencial indisciplinar dos EMGF: a emergência de outros sujeitos/objetos de perplexidade, de novas ferramentas analíticas e de abordagens interpretativas alternativas. Toda a marginalidade produz formas menos marginais de ser marginal. Abandonado o mito do binarismo linear, hoje sabemos que cada país central contém a sua periferia, que os movimentos sociais comportam lógicas internas de assimetria de poder, que as áreas mais emancipatórias de intervenção académica são crescentemente permeáveis às pressões internacionais para publicação em revistas indexadas. Há portanto várias margens na margem, e umas são mais margem que outras. À luz desta premissa, constatamos que os temas considerados pertinentes no âmbito dos EMGF em Portugal refletem uma padronização frequentemente concidente com as prioridades das agências de financiamento nacional e internacional à investigação e às organizações não-governamentaiss. Os casos da violência doméstica e do tráfico de pessoas para fins de exploração sexual são dois bons exemplos do enfoque convergente entre as agendas académica, estatal e associativa.

Mas o caráter interdisciplinar que alimenta os EMGF não se pode compadecer de um afunilamento temático. Da multiplicação de apostas em áreas de interesse diversas e arrojadas - incluindo as linhas de pesquisa incómodas, impróprias, insolentes - depende em larga medida a sua vitalidade e pertinência em tempos de tão rápidas transformações. Com efeito, a análise de temas que esca-

6 Numa lógica de maximizar os pontos de tradução, podemos pensar nas propostas em torno da Emancipatory Disability Research, em que, entre outros princípios, se postula o envolvimento das pessoas participantes no estudo nas mais diversas fases da investigação, incluindo formulação da candidatura, execução e disseminação. No fundo, trata-se de estender à academia a máxima ativista dos movimentos de pessoas 'deficientizadas' (Santos, A.C. e Santos, no prelo): nada sobre nós sem nós. 
pam aos cânones da produção feminista tem contribuído para a imprescindível atualização dos conhecimentos e procedimentos nos EMGF, contribuindo para colocar esta área de estudos na linha da frente do projeto emancipatório que recusa o poder vertical e se configura, intencionalmente, pouco dócil, articulando-se com uma ciência-cidadã, pública e não positivista.

Em anos recentes, também em Portugal os EMGF têm vindo a confrontar-se com temas até então invisíveis ou proscritos da academia. Para dar alguns exemplos: trabalho sexual (Duarte, 2012; Oliveira, A., 2011, 2013); poliamor (Cardoso, 2010); estudos transgénero (Rocha, 2012; Saleiro, 2010); teoria queer (Cascais, 2004; Coelho e Pena, 2009; Oliveira, J.M.d. et al., 2009; Santos, A.C., 2006, 2013); intersexo (Santos, A.L., no prelo); estudos feministas da deficiência (Santos, A.C. e Santos, no prelo); pornografia e pós-pornografia (Coelho, 2009; Rolo, 2011).

Em suma, o surgimento de temas que forçam à saída para fora da zona de conforto do mainstream que sempre ocorre mesmo dentro da margem é um dos desafios mais capacitantes - em termos teóricos e políticos - para qualquer área de estudos. No caso particular dos EMGF, a inclusão de temas insolentes apresenta a dupla vantagem de combater omissões epistemológicas e configurar uma ética feminista do cuidado, desta feita extensível às práticas silenciadas e secretas dos processos ortodoxos de investigação (Ryan-Flood e Gill, 2010).

Não deixa de ser ilustrativo o facto de que o cimento que une os dois elementos identificados - posicionalidades porosas e temas emergentes - é justamente a indisciplina. $\mathrm{O}$ potencial indisciplinador do campo interdisciplinar dos EMGF dota-o de particular atualidade e relevância no presente contexto político e científico, que valoriza o chamado «empreendedorismo» e a ciência aplicada, e é particularmente adverso à reflexão não-alinhada com essas prioridades. A indisciplina resulta da constatação de que, face a realidades fragmentadas, múltiplas, caleidoscópicas, não se torna possível, nem desejável, conter a produção de conhecimento em disciplinas dominantes (Browne e Nash, 2010; Halberstam, 2011, 2012). A disciplina é, além do mais, um mito inútil. Como refere Halberstam, «se o problema é demasiada aceitação a resposta deve ser uma sonora e feroz rejeição [...], uma política de queda-livre, pensamento selvagem e reinvenção imaginativa» (2012: xv). Não estamos ante um objeto acabado ou pretensamente estável; a pretensão, se existir, é a de reclamar a possibilidade do questionamento enquanto exercício político, o privilégio de reconhecer o caráter interseccional de todas as demandas, o arrojo de inovar mediante a reinvenção, descontrução e renovação a partir de todos os lugares im/possíveis, até a partir de dentro.

\section{O Dossier Temático}

Como acabámos de salientar, um dos contributos mais importantes dos debates feministas sobre epistemologia e metodologia é a reconcetualização da produção de conhecimento científico como uma prática sempre situada (Hara- 
way, 1988) e relacional. Nessa ótica, a posicionalidade das/os investigadoras/es, as dinâmicas afetivas e de poder das suas relações com as/os participantes, e os investimentos pessoais de investigadoras/es e participantes na investigação deixam de ser vistos como enviesamentos que "contaminam» a ciência, e passam a ser encarados como elementos vitais e generativos do processo de produção de conhecimento. $\mathrm{O}$ artigo de Mia Liinason e Marta Cuesta incluído neste dossiê, e intitulado Subjective emotions, political implications: Thinking through tensions and contradictions in feminist knowledge production, oferece um inspirador exemplo do extraordinário potencial epistémico e político desta forma de concetualizar o processo de investigação e as relações interpessoais que nele se estabelecem. As duas autoras dissecam de forma invulgarmente honesta e matizada as emoções que sentiram em diferentes momentos e encontros num estudo etnográfico sobre ativismo feminista na Suécia. Este tipo de narrativa reflexiva é considerado um elemento sine qua non da investigação feminista (Ramazanoğlu e Holland, 2002), mas várias/es autoras/es têm argumentado que acaba por funcionar, em muitos textos feministas, apenas como um exercício rotineiro, mecânico e vazio de "confissão», com pouca utilidade epistémica e política (Lather, 2007; Liinason, 2007). Liinason e Cuesta não caem nessa armadilha, utilizando as suas experiências pessoais como ponto de partida para produzir conhecimento riquíssimo sobre a interseccionalidade das relações de poder no feminismo, e a complexidade da negociação da identidade feminista.

Outra intervenção importante das críticas feministas à ciência dita mainstream tem sido o questionar daquilo que conta como "conhecimento». Muitas/os autoras/es feministas demonstram que a definição do que é «verdadeiro» ou «falso», «objetivo» e «subjetivo», mais ou menos «credível», não é neutra; pelo contrário, ela reflete e reproduz desigualdades estruturais, incluindo desigualdades de género. No seu artigo O poder do direito e o poder do feminismo: Revisão crítica da proposta teórica de Carol Smart, Paula Casaleiro problematiza essa questão no âmbito do direito. A autora argumenta que nas sociedades ocidentais contemporâneas é reconhecida ao direito a capacidade de estabelecer a "verdade» dos eventos, e que isso tem dado ao direito o poder de definir e desqualificar o conhecimento das mulheres, muitas vezes de forma opressiva. Recorrendo ao trabalho da socióloga Carol Smart e a exemplos de lutas travadas no campo jurídico e judicial pelo feminismo em Portugal, Casaleiro desmonta o modo como o direito desqualifica a experiência das mulheres e o conhecimento feminista. No entanto, procura afastar-se de uma leitura demasiado celebratória do feminismo e salienta a necessidade de fazer «uma análise crítica dos pressupostos epistemológicos das teorias feministas».

Essa componente de forte auto-reflexividade e auto-crítica guia também os textos de Gracia Trujillo e João Manuel de Oliveira. Gracia Trujillo, no seu artigo De la necesidad y urgencia de seguir queerizando y trans-formando el feminismo. Unas notas para el debate desde el contexto español, procede a um levantamento histórico acerca da intervenção feminista queer em meio académico e ativista, identificando 
obstáculos à sua efetiva inclusão nos EMGF no Estado Espanhol. Trujillo argumenta que a resistência em acolher propostas queer decorre da abordagem dominante no designado feminismo de Estado, cujo enfoque nas políticas de igualdade comporta dificuldades em esgrimir teórica e politicamente as demandas em torno do reconhecimento das diferenças. Nesse cenário, o feminismo «oficial» torna-se cúmplice da reprodução de um sistema binário de género pouco favorável a temas menos dominantes.

João Manuel de Oliveira, em A necropolítica e as sombras na teoria feminista, aprofunda a componente crítica já apontada por Trujillo, levando o seu argumento para o campo da contradição ética de uma teoria e prática (alegadamente) feministas que falham em reconhecer o caráter interseccional de todas as lutas por dignidade humana. Oliveira postula que, na ausência de processos de hifenização com temas como o antirracismo e a luta contra o neoliberalismo, o feminismo dominante incorre em riscos sérios de aprofundar, legitimando, o projeto colonialista e neoliberal.

O que oferecemos aqui, portanto, é um conjunto diversificado de artigos que nos convidam a refletir sobre dilemas metodológicos, desafios epistemológicos e debates teóricos, em Portugal como noutros contextos geográficos. Esperamos que a sua publicação possa servir como contributo para (re)animar e expandir a conversa sobre epistemologia e metodologia feminista em Portugal.

\section{Referências Bibliográficas}

Amâncio, Lígia (1994), Masculino e Feminino: A Construção Social da Diferença, Porto, Edições Afrontamento.

Amâncio, Lígia (2001), «O Género na Psicologia: uma História de Desencontros e Rupturas», Psicologia, XV, 1, pp. 9-26.

Amâncio, Lígia (2002), «O Género na Psicologia Social em Portugal», ex aequo, 6, pp. 55-75.

Amâncio, Lígia (2003), "O Género nos Discursos das Ciências Sociais», Análise Social, XXXVIII, 168, pp. $687-714$.

Araújo, Helena Costa (2002), «Há já Lugar para Algum Mapeamento nos Estudos sobre Género e Educação em Portugal? Uma Tentativa Exploratória», Investigar em Educação: Revista da Sociedade Portuguesa de Ciências da Educação, 1, pp. 101-146.

Araújo, Helena Costa, et al. (orgs.) (2003), ex aequo, 8 (Número especial: «Reconceptualizações Filosóficas e de Teoria Política-Perspectivas Feministas»).

Bebiano, Adriana, et al. (orgs.) (2009), Estudos Feministas: Ensaios de uma interdisciplina, Coimbra, Faculdade de Letras da Universidade de Coimbra.

Bebiano, Adriana, Ramalho, Maria Irene (2010), «Estudos Feministas e Cidadania Plena», Revista Crítica de Ciências Sociais, 89, pp. 5-10.

Browne, Kath, Nash, Catherine J. (orgs.) (2010), Queer Methods and Methodologies: Intersecting Queer Theories and Social Science Research, Farnham, Ashgate.

Cardoso, Daniel (2010), Amando Vári@s - Individualização, Redes, Ética e Poliamor, Dissertação de Mestrado, Faculdade de Ciências Sociais e Humanas da Universidade Nova de Lisboa. 
Cascais, António Fernando (org.) (2004), Indisciplinar a Teoria: Estudos Gays, Lésbicos e Queer, Lisboa, Fenda.

Coelho, Salomé (2009), «Por um Feminismo Queer: Beatriz Preciado e a Pornografia com Pre-textos», ex aequo, 20, pp. 29-40.

Coelho, Salomé, Pena, Cristiana (2009), «Da INTERvenção à INTRAvenção: Pistas para um Activismo Lésbico-Feminista», LES Online, 1, 1, pp. 3-11.

Downey, Gary Lee, et al. (1997), «Corridor Talk», in J. Dumit e G. L. Downey (orgs.), Cyborgs \& Citadels: Anthropological Interventions in Emerging Sciences and Technologies, Santa Fe, School of American Research Press, pp. 245-264.

Duarte, Madalena (2012), «Prostitution and Trafficking in Portugal: Legislation, Policy, and Claims», Sexuality Research and Social Policy, 9, 3, pp. 258-268.

Duarte, Madalena (2013), Para um Direito sem Margens: Representações sobre o Direito e a Violência contra as Mulheres, Tese de Doutoramento, Faculdade de Economia da Universidade de Coimbra.

Ferreira, Virgínia (2001), «Estudos sobre as Mulheres em Portugal: a Construção de um Novo Campo Científico», ex aequo, 5, pp. 9-25.

Ferreira, Virgínia (2004), Relações Sociais de Sexo e Segregação do Emprego: Uma Análise da Feminização dos Escritórios em Portugal, Tese de Doutoramento, Universidade de Coimbra.

Fonow, Mary Margaret, Cook, Judith A. (2005), «Feminist Methodology: New Applications in the Academy and Public Policy», Signs: Journal of Women in Culture and Society, 30, 4, pp. 2211-2236.

Fonseca, Laura (2001), Culturas Juvenis, Percursos Femininos: Experiências e Subjectividades na Educação de Raparigas, Oeiras, Celta.

Grünell, Marianne e Kas, Erna (1995), «Modernization and Emancipation from Above: Women's Studies in Portugal», European Journal of Women's Studies, 2, 4, pp. 535-545.

Halberstam, J. Jack (2011), The Queer Art of Faillure, Durham, Duke University Press.

Halberstam, J. Jack (2012), Gaga Feminism: Sex, Gender, and the End of Normal, Boston, Beacon Press.

Haraway, Donna (1988), «Situated Knowledges: The Science Question in Feminism and the Privilege of Partial Perspective», Feminist Studies, 14, 3, pp. 575-599.

Harding, Sandra e Norberg, Kathryn (2005), «New Feminist Approaches to Social Science Methodologies: an Introduction», Signs: Journal of Women in Culture and Society, 30, 4, pp. $2009-2015$.

Joaquim, Teresa (2001), «Os Estudos sobre as Mulheres em Filosofia», ex aequo, 5, pp. 69$-107$.

Joaquim, Teresa (2004), «ex aequo: Contributo Decisivo para um Campo de Estudos em Portugal», Revista Estudos Feministas, 12, 3, pp. 88-93.

Joaquim, Teresa (2007), «Feminismos, Estudos sobre as Mulheres, ou "Para Onde Vai Este Barco?"», in Lígia Amâncio, et al. (orgs.), O Longo Caminho das Mulheres: Feminismos 80 Anos Depois, Lisboa, Publicações Dom Quixote, pp. 203-216.

Lather, Patti (2007), «Postmodernism, Post-structuralism and Post(Critical) Ethnography: Of Ruins, Aporias and Angels", in Paul Atkinson, et al. (orgs.), Handbook of Ethnography, London, Sage, pp. 477-492.

Levy, Teresa, Queiroz, Clara (orgs.) (2006), Ciência e Género. Quatro Textos de Quatro Mulheres, Lisboa, Centro de Filosofia das Ciências da Universidade de Lisboa.

Liinason, Mia (2007), «Who's the Expert? On Knowledge Seeking as Praxis: a Methodological Approach», Graduate Journal of Social Science, 4, 2, pp. 40-60.

Macedo, Ana Gabriela (2012), «O Feminismo como Aracnologia e Indisciplina: Tópicos 
para Repensar o Feminismo Hoje», in Sofia Neves (org.), Género e Ciências Sociais, Castêlo da Maia, Edições ISMAI, pp. 41-47.

Macedo, Ana Gabriela (org.) (2002), Género, Identidade e Desejo: Antologia Crítica do Feminismo Contemporâneo, Lisboa, Cotovia.

Macedo, Ana Gabriela, Amaral, Ana Luísa (2002), «A Palavra, a Identidade e a Cultura Translativa: Para uma Introdução ao Dicionário Terminológico de Conceitos da Crítica Feminista», in Maria Irene Ramalho e António S. Ribeiro (orgs.), Entre Ser e Estar: Raízes, Percursos e Discursos de Identidade, Porto, Edições Afrontamento, pp. 383-408.

Macedo, Ana Gabriela, Amaral, Ana Luísa (orgs.) (2005), Dicionário da Crítica Feminista, Porto, Edições Afrontamento.

Magalhães, Maria José (1998), Movimento Feminista e Educação em Portugal: Décadas de 70 e 80, Oeiras, Celta Editora.

Magalhães, Maria José (2001), «Dez Anos da APEM: Percorrer as Vozes, Significar os Percursos», ex aequo, 5, pp. 27-68.

Magalhães, Maria José (2005), Mulheres, Espaços e Mudanças: o Pensar e o Fazer na Educação das Novas Gerações, Tese de Doutoramento, Universidade do Porto.

Neves, Sofia (2010), «"Não Nasci Feminista... Tornei-me Feminista”: Reflexões em Torno do Passado e do Presente, com os Olhos Postos no Futuro», in Maria José Magalhães, et al. (orgs.), Quem tem Medo dos Feminismos? (Vol. I), Lisboa, Nova Delphi, pp. 37-43.

Neves, Sofia (2012), «Género e Ciências Sociais...ou Quando a Ciência Também é Política...», in Sofia Neves (org.), Género e Ciências Sociais, Castêlo da Maia, Edições ISMAI, pp. 15-24.

Neves, Sofia, Nogueira, Conceição (2004), «Metodologias Feministas na Psicologia Social Crítica: a Ciência ao Serviço da Mudança Social», ex aequo, 11, pp. 123-138.

Neves, Sofia, Nogueira, Conceição (2005), «Metodologias Feministas: a Reflexividade ao Serviço da Investigação nas Ciências Sociais», Psicologia: Reflexão e Crítica, 18, 3, pp. 408-412.

Nogueira, Conceição (2001a), «Construcionismo Social, Discurso e Género», Psicologia, XV, 1, pp. 43-65.

Nogueira, Conceição (2001b), Um Novo Olhar sobre as Relações Sociais de Género: Feminismo e Perspectivas Críticas na Psicologia Social, Lisboa, Fundação Calouste Gulbenkian.

Nogueira, Conceição (2004), «Editorial», ex aequo, 11, pp. 5-11.

Nogueira, Conceição (2012), «Introdução à Teoria da Interseccionalidade nos Estudos de Género», in S. Neves (org.), Género e Ciências Sociais, Castêlo da Maia, Edições ISMAI, pp. 67-78.

Oliveira, Alexandra (2011), Andar na Vida: Prostituição de Rua e Reacção Social, Coimbra, Almedina.

Oliveira, Alexandra (2013), «Prostituição Feminina, Feminismos e Diversidade de Trajetórias», ex aequo, 28, pp. 81-96.

Oliveira, João Manuel de (2009), Uma Escolha que Seja Sua: uma Abordagem Feminista ao Debate Sobre a Interrupção Voluntária da Gravidez em Portugal, Tese de Doutoramento, ISCTE.

Oliveira, João Manuel de (2010), «Os Feminismos Habitam Espaços Hifenizados - A Localização e Interseccionalidade dos Saberes Feministas», ex aequo, 22, pp. 25-39.

Oliveira, João Manuel de (2012), «Fazer e Desfazer o género: Performatividades, Normas e Epistemologias Feministas», in Sofia Neves (org.), Género e Ciências Sociais, Castêlo da Maia, Edições ISMAI, pp. 49-66.

Oliveira, João Manuel de, Amâncio, Lígia (2006), «Teorias Feministas e Representações Sociais: Desafios dos Conhecimentos Situados para a Psicologia Social», Revista Estudos Feministas, 14, 3, pp. 597-615. 
Oliveira, João Manuel de, et al. (2009), «Feminismos Queer: Disjunções, Articulações e Ressignificações», ex aequo, 20, pp. 13-27.

Pereira, Maria do Mar (2011), Pushing the Boundaries of Knowledge: An Ethnography of Negotiations of the Epistemic Status of Women's, Gender, Feminist Studies in Portugal, Tese de Doutoramento, London School of Economics and Political Science.

Pereira, Maria do Mar (2012a), Fazendo Género no Recreio: a Negociação do Género em Espaço Escolar, Lisboa, Imprensa de Ciências Sociais.

Pereira, Maria do Mar (2012b), ««Feminist Theory is Proper Knowledge, But...»: The Status of Feminist Scholarship in the Academy», Feminist Theory, 13, 3, pp. 283-303.

Pinto, Teresa (2007a), «Editorial», ex aequo, 16, pp. 5-8.

Pinto, Teresa (2007b), «História das Mulheres e do Género: Uma Progressiva Presença Institucional de Dúbia Legitimação Académica», ex aequo, 16, pp. 141-166.

Pinto, Teresa (2008), A Formação Profissional das Mulheres no Ensino Industrial Público (1884-1910): Realidades e Representações, Tese de Doutoramento, Universidade Aberta.

Pinto, Teresa (2009), «Editorial», ex aequo, 20, pp. 5-6.

Ramalho, Maria Irene (2001), «Os Estudos sobre as Mulheres e o Saber: Onde se Conclui que o Poético é Feminista», ex aequo, 5, pp. 107-122.

Ramazanoğlu, Caroline, Holland, Janet (2002), Feminist Methodology: Challenges and Choices, London, Sage.

Ribeiro, António Sousa, Ramalho, Maria Irene (1998/1999), «Dos Estudos Literários aos Estudos Culturais?», Revista Crítica de Ciências Sociais, 52/53, pp. 61-83.

Rocha, Anabela (2012), Outro Género de Corpos: O Materialismo Tecnológico Fisicalista de Beatriz Preciado, Dissertação de Mestrado, Faculdade de Ciências Sociais e Humanas da Universidade Nova de Lisboa.

Rolo, Inês (2011), «Dildo, Meu Amor (Reflexivo)», Revista Invisivel, edição zero [em linha] disponível em https://www.academia.edu/959760/Dildo_meu_amor_reflexivo [consultado a 16 de fevereiro de 2014].

Ryan-Flood, Róisín, Gill, Rosalind (orgs.) (2010), Secrecy and Silence in the Research Process: Feminist Reflections, Abingdon, Routledge.

Saleiro, Sandra Palma (2010), «Transexualidade e Transgénero em Portugal: Dois "Vazios" em Debate», in Manuel Carlos Silva, et al. (orgs.), Actas do X Congresso Luso-Afro Brasileiro de Ciências Sociais: Sociedades Desiguais e Paradigmas em Confronto. Vol. IV Familia, Género e Sexualidades, Braga, Universidade do Minho, pp. 84-90.

Santos, Ana Cristina (2012), «Disclosed and Willing: Towards A Queer Public Sociology», Social Movement Studies, 11, 2, pp. 241-254.

Santos, Ana Cristina (2013), Social Movements and Sexual Citizenship in Southern Europe, Houndmills, Palgrave Macmillan.

Santos, Ana Cristina (org.) (2006), Revista Crítica de Ciências Sociais, 76 (Número especial: «Estudos Queer: Identidades, Contextos e Acção Colectiva»).

Santos, Ana Cristina, Santos, Ana Lúcia (no prelo), «Yes, We Can - Challenging the Mis/fit Sexual Body in Disabled Women's Narratives», TESG (Tijdschrift voor Economische en Sociale Geografie - Journal for Economic and Social Geography), número temático organizado por Valerie De Craene.

Santos, Ana Lúcia (no prelo), «Para lá do Binarismo? A Intersexualidade como Desafio Epistemológico e Político», Revista Crítica de Ciências Sociais, 102.

Schouten, Maria Johanna (2011), Uma Sociologia do Género, Vila Nova de Famalicão, Edições Húmus.

Strathern, Marilyn (1988), The Gender of the Gift: Problems with Women and Problems with Society in Melanesia, Berkeley, University of California Press. 
Tavares, Manuela (2011), Feminismos em Portugal: Percursos e Desafios, Lisboa, Texto Editora.

Tavares, Manuela, et al. (2012), «O Debate Epistemológico nos Estudos Feministas», in Sofia Neves (org.), Género e Ciências Sociais, Castêlo da Maia, Edições ISMAI, pp. 25-40.

Threadgold, Terry (2000), «Gender Studies and Women's Studies», Australian Feminist Studies, 15, 31, pp. 39-48.

Vale de Almeida, Miguel (1995), Senhores de Si: Uma Interpretação Antropológica da Masculinidade, Lisboa, Fim de Século.

Vale de Almeida, Miguel, et al. (1996), «O Género nas Ciências Sociais: Interdisciplinaridade, Inovação, Crítica», in Dinâmicas Culturais: Novas Faces, Outros Olhares (Vol. II), Lisboa, Edições do Instituto de Ciências Sociais, pp. 129-144. 